\title{
Coming to grips with dynamics and complexity. Methodological challenges to real-life writing research
}

\section{Daniel Perrin}

\section{Introduction}

Linguistics first considered written language, later focused on conversations as processes, and only then rediscovered written language from a process perspective. Whereas psycholinguistic research on writing focuses on key logging and eye tracking to analyze micro processes such as planning between linguistic units in experimental settings, sociolinguistics and applied linguistics start relating writing practices in the field to social macro structures and problems such as societal diversity and change. In doing so, they understand micro development as a methodologically accessible activity which stands for similar, but less accessible developments on higher levels and timescales.

In my article, I discuss the methodological potential of research frameworks in "real-life" writing research, drawing on newswriting as an upcoming field of application. After a short overview of four more traditional research frameworks in the research of newswriting, I focus on Dynamic Systems Theory (DST). ${ }^{1}$ I argue that DST thinking fosters appropriate approaches to explaining the complexity of writing in multi-layered realworld contexts. On the one hand, DST provides the conceptual metaphors needed to understand why and how it makes sense to systematically analyze a world in which everything is connected. On the other hand, DST enables researchers to develop empirically grounded models of processes at the edge of chaos - processes such as dealing with time pressure, poor quality pictures and emergent ideas when writing a piece of news.

In this article, I focus on DST's potential for explaining the dynamics and complexity of writing processes in real-world contexts such as the domain of newswriting. ${ }^{2}$ A newswriting process by an experienced journalist about demonstrations in Lebanon, is referred to throughout, as a case of such real-world writing. On an empirical level, I exploit data from this LEBANON case to show that changing a single word in an emerging news text can mean reframing both the writing process and the text product. On a 
theoretical level, I draw on the LEBANON case to explain how and why DST helps researchers conceptualize and model the complexity of newswriting.

First, I situate DST within a set of conceptually related research frameworks that have proved valuable in the investigation of text production (Part 2). Then, I elaborate on the key concepts of DST from five relevant perspectives: Investigating text production processes as dynamic systems means reconstructing their structure and dynamics, that is their elements and relations (Part 3) as well as their processes, their stability and change (Part 4). Beyond explaining what systems actually consist of and do, DST then evaluates dynamic alternatives: what a system, at any state, could do and why (Part 5). Finally, an explanation is needed as to how the dynamic system maintains its identity despite change (Part 6). Such research produces outcomes mapping micro development and macro perspectives: for example, situated knowledge about emergence in collaborative text production, or empirically-grounded models of writing phases (Part 7).

\section{Dynamic Systems Theory as a framework for writing research}

Research frameworks provide basic ontological, epistemological and methodological assumptions: they offer scientifically-justified solutions to the problem of what can be discovered about which objects of study and why this matters. In doing so, such a framework organizes the way research questions emerge and are formulated, data are gathered and analyzed, findings are generated and interpreted, and theories are developed and applied. Thus, deciding on a particular research framework or combination of frameworks means focusing on particular aspects of the object under investigation - and putting less priority on others. Several research frameworks have proved useful in the investigation of language in general, language use, or even writing in particular (Perrin 2012).

In product-related frameworks, researchers primarily draw on final communicational offers such as written texts or media items in order to scrutinize public discourse from an external point of view. Ethnographic research (EG), in addition, aims at understanding its objects of study from an insiders' perspective and relate it to the researchers' external perspective. Ethnographic researchers are interested in discovering what the people and communities under investigation actually do and why they do it, in other words, why it makes sense to them. Thus, writing research in ethno- 
graphic research frameworks focuses on processes of text production and on sense-making practices of writers instead of only analyzing products.

Historically, classical ethnography tends to be limited to single case studies. Writing research can overcome this limitation by combining ethnography with other research frameworks (Table 1):

1. with Grounded Theory (GT), in order to systematically develop empirically grounded theories;

2. with Transdisciplinary Action Research (TD), in order to systematically share knowledge with the practitioners involved and to jointly solve practical problems;

3. with Realist Social Theory (RST), in order to systematically relate situated activity such as language use to social macro structures, such as social settings and contextual resources; and

4. with Dynamic Systems Theory (DST), in order to model conditions that foster emergence and functional change in complex dynamic settings.

Table 1. Combining ethnography with newer research frameworks, with references to exemplary theoretical discussions.

\begin{tabular}{|c|c|c|c|c|c|}
\hline & EG & GT & TD & RST & DST \\
\hline 站 & $\begin{array}{l}\text { relating } \\
\text { perspectives }\end{array}$ & theory building & mutual learning & contextualizing & $\begin{array}{l}\text { fostering } \\
\text { emergence }\end{array}$ \\
\hline ్ㅗ & case study & $\begin{array}{l}+ \\
\text { generalization }\end{array}$ & $\begin{array}{l}+ \\
\text { real-world } \\
\text { problem }\end{array}$ & $\begin{array}{l}+ \\
\text { macro structure }\end{array}$ & $\begin{array}{l}+ \\
\text { dynamics }\end{array}$ \\
\hline & Lillis, 2008 & $\begin{array}{l}\text { Tavory \& } \\
\text { Timmermans, } \\
2009\end{array}$ & Agar, 2010 & Sealey, 2007 & Agar, 2004 \\
\hline
\end{tabular}

DST originated in biology, mathematics, and physics. Later, it was applied to mental and social processes. Today, DST deals with systems as varied as evolution, weather, business organizations Recently, DST has widely been viewed as an especially promising approach in research into language use.

In their position paper, Beckner et al. (2009) propose a DST approach to explain how language is acquired and used, and how it changes. Cameron and Deignan (2006), Ellis and Larsen-Freeman (2006), Lantolf (2006), Larsen-Freeman (2006), and MacWhinney (2006) focus on emergence in 
the development, acquisition, and use of language. As Larsen-Freeman and Cameron (2008: 18-19), argue, sociocultural, interactionist, systemic, integrationist, and ecological approaches to language (e.g. Vygotski (1978), Halliday (1973), Harris (1993), Sealey and Carter (2004)) overlap with DST in their basic asumption that language use, and mental, linguistic, and societal structures are interconnected.

Systems such as languages are dynamic: they change continually as their elements and contexts interact. In the context of newswriting for example, if journalists invent new words and these words become part of the general vocabulary over time, then language is changed through language use - with impacts upon further language use. DST is a research framework focusing on principles of change.

Depending on the system, change can be discrete, linear and completely predictable, such as when the flow of traffic is controlled by stoplights. In contrast, language change as well as conversations and text production are complex dynamic processes; they are not entirely predictable. Explaining them needs to take into account processes and interrelations from individual to global levels and from short to long-term time frames. Therefore DST treats the complexity and dynamics of its object as integrally as possible.

\section{Structures: Zooming through levels and timescales}

One of the key questions for DST is what a dynamic system consists of at a given point in time. When DST focuses on structure, it describes the elements and relations of the system under investigation, its nested levels and timescales, the openness for interaction with other systems, and the context.

In DST, a written text can be seen as the frozen state of the dynamic system of newswriting. Different kinds of semiotic elements, such as letters, words, sentences, paragraphs, and pictures, are interrelated in a way that the news item can evoke complex mental representations in the dynamic system of reading or listening to and understanding news. In the Lebanon case, the journalist R.G. produced the following text about demonstrations in Saida (Table 2). It was broadcast on the $14^{\text {th }}$ of February 2007, in the French news program JOURNAL of the Swiss public broadcaster SRG SSR. 
Table 2. Key pictures and translated text of the news item produced in the LEBANON case. The context: In Lebanon, ethnic and religious diversity as well as expansion plans of neighboring countries are threats to national unity. In 2005 the Lebanese Prime Minister, Rafic Hariri, was killed in a bomb attack. While European media often report on politically motivated violence in Lebanon, this item foregrounds peaceful demonstrations on the second anniversary of Hariri's assassination.

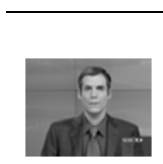

00:00:00 | anchor's introduction

In Lebanon, on a day of high tension in Beirut where the assassination of R. H, two years ago, is being commemorated, thousands of faithful of the former prime minister poured into Martyrs' Square this morning in the centre of the Lebanese capital. A demonstration flanked by a plan of maximum security measures. R $[. .] \quad G.[\ldots]$

\section{0:00:18 | offtext}

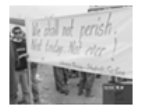

The Lebanese do not work on this anniversary day. They instead have come by the tens of thousands from all over the country. From Tripoli in the north or from Saida in the south. Saida - the city of Rafic Hariri, assassinated two years ago to the day. They have come by road and some also by the tranquil path of the Mediterranean. What all the demonstrators have in common: the Lebanese flag to express the love they avow for their quartered country which is coveted by troublesome neighbors.

\section{0:00:47 | quote man}

We are here for Rafik Hariri and all the martyrs. And to say the truth: I protest against Syria.

\section{0:00:57 | quote woman}

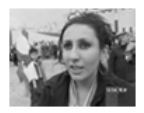

We want culture, education, public transportation, not arms. We wish to learn, make progress, and live a normal life like everyone else.

\section{0:01:07 | offtext}

The demonstration is orchestrated by the anti-Syrian majority, currently in power but whose legitimacy is contested by the opposition forces, led by the shiites of Hezbollah. Where the fear of new violence today, is again resounding in people's heads so much, the two explosions that went off yesterday morning on the Christian mountain very close by. Two unattributed attacks but doublethe warning to the Lebanese army, the only guarantee of the country's unity at the moment.

Just like the written text or a writing process, every system consists of interacting elements and relations producing a certain overall behavior at a 
given time. In a DST view, elements can be dynamic systems themselves. A newsroom, for example, can then be seen as a dynamic system consisting of other dynamic systems such as individuals, peer groups, organizations, roles, rules, expectations, tasks, products, processes, money, time allocations, and so on. This dynamic system is embedded in contexts such as audience, sources, public sphere, and competitors in media markets. In a TV newsroom, this interplay results in overall activities such as broadcasting at airtimes and conferencing, newsgathering, and newswriting in between (Figure 1). ${ }^{3}$

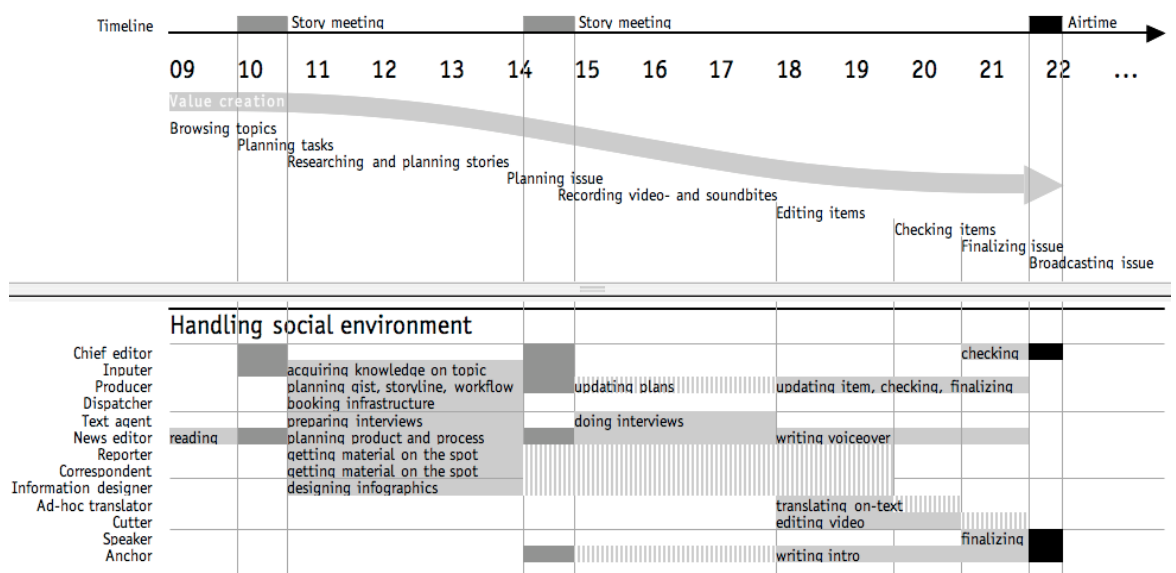

Figure 1. Timeline, roles, and tasks as key elements of the workflow structure in a newsroom.

However, behavior in such a system happens on various nested and interconnected levels and timescales: from the milliseconds of neural processing to the minutes of newswriting, hours of daily production cycles, years of organizational restructuring, decades of professional careers, centuries of language change, and eons of evolution. On some levels such as newswriting or daily production cycles, the agents are mostly aware of their activity, on others, the system behaves beyond the agents' awareness.

Open systems allow and need particular input and output to maintain their stability. Resources such as source texts enter the dynamic system of newswriting from outside; products such as news items are the output. The dynamic system of writing a single news item ends when the deadline is reached or the item is submitted to be broadcast.

Ignoring the deadline when writing a single news item could affect the context of this system, namely the overall system that produces news con- 
tinuously. Conversely, the unpleasant experience of lack of content at airtimes could trigger a stricter management of deadlines and thus change the contextual constraints for the next newswriting processes. Thus, dynamic system and contexts are mutually and inseparably connected. A dynamic system can initiate changes in its contexts and it can also adapt to changes in its contexts. This is why DST treats context as a part of the complexity and dynamics of a system under investigation.

\section{Dynamics: Tracking change in context}

What happens with the dynamic system over time? When DST focuses on dynamics instead of structure, it describeshow systems change, why this often takes place in a non-linear fashion, and how stability and variability of the system are balanced as stability in motion. Change in the system of writing a single news item for example can take the system from smooth writing-down phases (Figure 2, phases $\mathrm{A}$ and $\mathrm{B}$ ) to volatile phases where the emerging text is restructured ( $\mathrm{D}$ and $\mathrm{E})$ :
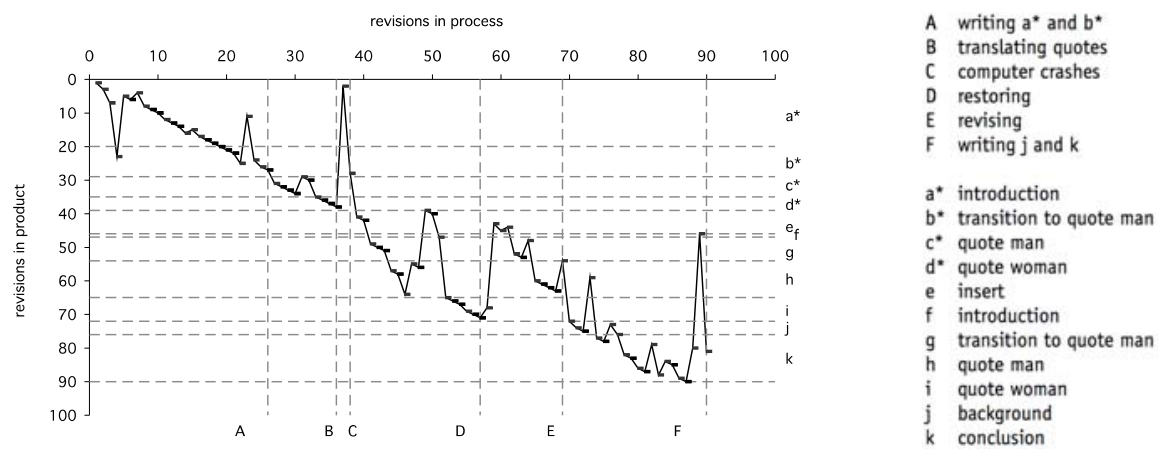

Figure 2. Progression graph of the LEBANON writing process, illustrating linear and non-linear change in the system of writing a news item. Progression graphs indicate how the writer moved the cursor through the developing text. These cursor movements are interpreted as the writer's shifts in focus. The temporal sequence of revisions in the writing process is represented on the ordinal scale of the $\mathrm{x}$-axis; the spatial sequence of revisions in the text product shows on the y-axis, also ordinal. ${ }^{4}$

In a DST view, systems are always open to change. Elements, relations, and contexts change in their specific timescales as they interact. In this 
multilevel flow of change, the future states of a dynamic system continuously depend on the respective present states. In the dynamic system of collaborative newswriting, even highly routinized and standardized procedures such as writing a newsflash or embedding a quote are adapted to context each time they are performed. Moreover, revising a peer's text under time pressure can end in rewriting the item and offhand comments about the peer's writing style; the comments can initiate changes in procedures and policies - which in turn will affect future collaboration in newswriting. Returning to the LEBANON case, a linear flow of words into stretches of language on the screen can suddenly be interrupted, for example in order to delete and replace a previously written word (Figure 3):

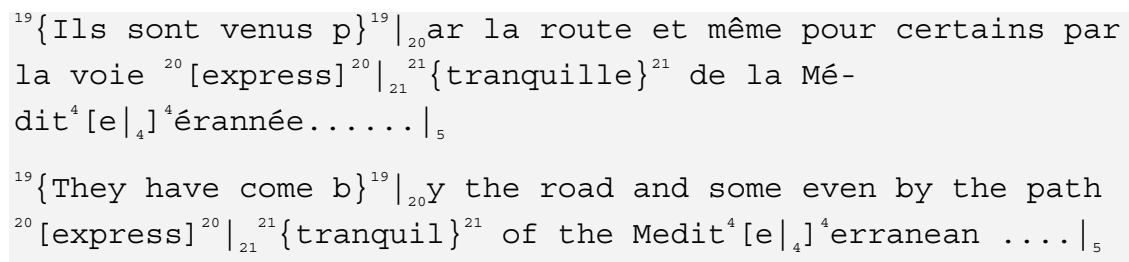

Figure 3. Excerpt and English translation of S-notation, showing deletions in ${ }^{\mathrm{n}}[\text { square brackets }]^{\mathrm{n}}$ and insertions in ${ }^{\mathrm{n}}\{\text { curly braces }\}^{\mathrm{n}}$. Wherever the writing is interrupted to delete or add something, S-notation inserts the break-character $\left.\right|_{\mathrm{n}}$. The subscript and superscript numbers indicate the order of the steps: Right after having inserted "Ils sont venus", the author jumps forward to delete "express" and insert "tranquille". 5

Such complex changes are not random, but neither are they completely predictable. New system properties may emerge when a dynamic system adapts to context. As these new properties can change the way a dynamic system behaves, they also can alter the way the system changes. Therefore, change can be non-linear: sudden, radical, dramatic, turbulent, and chaotic instead of smooth, continuous, and steady. New words on the screen can trigger new ideas in the mind of the writer and thus set off a story in an unpredictable direction.

Another example of the unpredictability of complex processes: in the research project that the LEBANON case was part of, coping with overbooked cutting rooms proved to be an important factor of success on the logistic level of newswriting. However, from a DST point of view, this does not mean that providing additional cutting rooms would augment wellbeing, efficiency or text quality. If a newsroom were a simple system, behaving linearly, then adding more workplaces for cutters would proportionally 
shorten the waiting line of journalists wanting to cut their videos. In a nonlinear DST scenario, however, easier access to video workplaces can discourage planning and eventually extend the wait. In an alternative nonlinear scenario, easier access motivates experimentation; new, more effective strategies of cutting might emerge, the cutting time per news item would decrease, and many of the new workplaces would remain underutilized.

The emergence of new strategies in the non-linear scenarios can start by varying the cutting procedures or lexical choices and end in different fundamental changes in the overall behavior of the dynamic system. Variability being the seed of change, capturing local variation around stabilized ways of activity is crucial for DST. In contrast to top-down research, DST thus considers variability as data, not as noise. Smoothing away seemingly senseless details and variability, for instance by statistical averaging, would mean losing crucial information for detecting emergence and explaining change. Thus, the lexical change in the example above from "voie express" to "voie tranquille" could be crucial and deserves attention, as discussed below.

\section{Evaluation: Identifying the control parameters of change}

Of all the various possibilities, what does a dynamic system do at a particular moment in time? When DST focuses on evaluation, it outlines the state space as the landscape of the potential trajectories the dynamic system under investigation could follow on its way from state to state through shifts. Attractors in this state space stabilize the system, and control parameters determine its trajectory.

The overall behavior of a system at a given time is called a state. A shift is the dramatic change between very different states of a system. At a particular moment, a system is in a particular state, performing a particular pattern of behavior. The synopsis of all possible states of the system is its state space. In the example of the newsroom, the state space includes three typical states: conferencing, newswriting, and broadcasting. The simplified system of the newsroom shifts cyclically from one state to the next on its trajectory through the state space. A very different state shift can be observed in the LEBANON case:

After the journalist R.G. had written the first two paragraphs and translated the selected quotes himself from a written English translation received 
from the news service, the computer crashed. The translations were not saved, so R.G. had to do them again before writing the last three paragraphs. This crash and other computer problems increased the time pressure, in particular for the cutter who, as R.G. says, then had to rely on R.G. for the story instead of asking critical questions.

The more finely graded analysis of a dynamic system is, the greater the number of states in the state space. In the newsroom, the state of newswriting then might expand to three states: DEFINING THE TASK, WRITING THE TEXT, and IMPLEMENTING THE PRODUCT. The state of WRITING THE TEXT can further expand to SETTING THE GOAL, PLANNING THE TEXT, CONTROLLING THE WRITING FLOW, and REVISING THE TEXT. No matter how fine the gradation, change will happen smoothly within the preferred states and dramatically in the shifts between them.

The states into which a dynamic system preferably moves are called attractors. The simplified system of the newsroom moves cyclically among the three attractors CONFERENCING, NEWSWRITING, and BROADCASTING. Such attractors are called cyclic attractors. In addition to this type, there are two others. The fixed point attractor is where a dynamic system prefers to settle down. In a dynamic system of writing a single news item, a fixed point attractor is reached when the final version of the text is ready for publication. On a more general level, reaching expertise is a fixed point attractor in the dynamic system of a professional's trajectory. In the LEBANON case, the journalist R.G. can be considered close to this attractor:

R.G. (born in 1959) did a degree in modern languages, took a 6-month trip around the world to " 20 or 30 countries", wrote four suitcases full of travel diaries that he still reads, and produced short films ("three to four minutes long") for a TV travel show ("Trip around the World"). ${ }^{6} \mathrm{He}$ completed a two-year program in journalism and was a journalist at RADIO SUISSE ROMANDE, the French-speaking public service radio station in Switzerland, for 20 years. In the first 10 years, he worked on the local desk and after that in foreign affairs, which involved a lot of travel. ${ }^{7}$ On the side, he helped set up an agency for which he produced foreign television reportages. R.G. still travels a lot; in the previous year for instance, he was in Lebanon.

In contrast to the fixed-point attractor, the strange attractor is where a system shows high responsiveness and unstable behavior; a minor change in input can produce a dramatic change in behavior. Looking for outstanding pictures among masses of uninteresting ones is such a strange attractor in the trajectory of the dynamic system of newswriting. The system remains 
in this highly unstable, critical state until, suddenly, pictures are found that are considered ineresting enough as a visual starting point for the news item or parts of it. Influenced by these formarly unknown pictures, the system of newswriting then moves on.

In the LEBANON case, the journalist R.G. received the assignment to prepare an item about demonstrations in Lebanon three hours before airtime. Since R.G. knows his way around Lebanon and had been there recently, he said he felt familiar with the topic. He read an ample amount of text too and received lots of visual material - two hours of images from Lebanese TV, mostly crowds of people with placards. In addition, he obtained video recordings of two interviews with demonstrators. Although he found two passages in them with relevant quotes, he said he found it an effort to make the material vibrant.

An attractor thus draws the dynamic system like a magnet. It is easy for the system to move into a strong attractor, but once it is there, a push is needed to overcome stability and send the system out into the state space again. In the newsroom example, it takes such a push to get people ready for the newsroom conference in time. Towards the end of the conference, it can be hard to finish on time and then start researching. The same goes for the transitions between activities of text production: once in research mode, writers might find it hard to stop gathering information and start writing. In text production mode, some feel more attracted to revising the text they have written so far than to composing new text. Finally, close to the deadline, they might have problems to stop revising and post their items for publication. In the LEBANON case, following the examples of most western media by reproducing the well-known stories of violence was such a strong attractor the journalist had to overcome:

R.G. limited himself to the main topic, "a photograph" of the demonstrations starting on the martyrs' square. ${ }^{8}$ He consciously abstained from biographical background information and spectacular pictures of the assassination of the former prime minister of Lebanon that the demonstrators were commemorating, since the assassination had already been shown many times. Moreover he decided not to start with pictures of the demonstration themselves. Instead, he first showed the people arriving in masses to demonstrate.

The pushes to overcome attractors come from drivers in the dynamic system. The drivers help the system move around the state space, avoid certain attractors, meet others, and leave them again. Motivation is an example of such a driver, helping a dynamic system of reflexive newswriting 
to switch between the attractors of routinized activity and purposeful learning. This means alternating between newswriting routines and breaking out of these routines, trying out new procedures, and enhancing repertoires of writing strategies and techniques. As the drivers control the trajectory of the dynamic system in its state space, they are also called control parameters. Knowing what they are facilitates interventions to the system, for instance in coaching sessions. In the LEBANON case, the journalist's experience and, at the same time, his openness to the unexpected worked as drivers.

In an early, linear phase in the writing process (revisions 1-25, see Figure 2), R.G. wrote the voice-over for the introductory scene. The scene shows how people traveled en masse to the demonstration in boats. Finding these boats in the video material surprised him, he says. ${ }^{9}$ In his very first sentence, R.G. refers to another fact new to him: as he just learns from the news service, the Lebanese had that day off. So the beginning of the product was shaped by details that were new to the experienced journalist.

After a closer look at the pictures that were new to him, he then adjusted a word that turned out to be a key word for the whole writing process. R.G. had first talked about an expressway to describe the direct route over the Mediterranean Sea ("la voie express de la méditerrannée"). While interweaving the text with the images he realized that a tranquil path ("la voie tranquille") would better fit the slow journey of a boat. So he deleted "express" and inserted "tranquille" instead (Figure 3). With this revision, cued by new details and R.G.'s language awareness, the design of the item emerged: R.S. started combining strong symbols.

\section{Identity: Explaining emergence and stability in motion}

Despite change, a dynamic system must maintain its identity; otherwise, there would be no reason to conceptualize it as an entity in space and time. How does the dynamic system persist in the face of change? When DST focuses on identity, it explains stability in motion, cycles of emergence in the light of co-adaptation and self-similarity.

As change never stops, any perceived stability of a dynamic system is stability in motion, an equilibrium in continuous adaptation and change for a certain period, between more dramatic phases of change. ${ }^{10}$ Changes on one level of a dynamic system can lead to categorically new, emergent properties on a higher level. 
Such emergence happens, for example, if revising and criticizing single news reports triggers changes in style policies or if missed deadlines stimulate a media organization to optimize its workflows. The emergent new properties on the higher level of the dynamic system then affect activity on lower levels, for instance stylistic choice or process planning in newswriting. Whereas activities such as qualified criticism or missing deadlines can be identified ex post as some of the reasons for the emergence, it is hardly predictable which specific activity will cause a shift in state. Thus, emergence produces a new whole which is not reducible to and not explainable by the sum of its parts. ${ }^{11}$ In the LEBANON case, deciding on the formulation of "voie tranquille" provides the journalist with the idea of using leitmotifs: strong symbols standing for key properties, such as tranquility, that recur and scale throughout levels and time frames of the object.

With "tranquille" R.G. found the leitmotif of his item. He says that he loves the adjective because it corresponds not only to the image of the boats but also to the tranquility of the demonstration. He expects the "tranquil" to resonate in the minds of the audience. ${ }^{12}$ Just as consciously, he talks about using the term drapeau libanais (Lebanese flag) as a symbol of the demonstrators' desire for political independence. The same is true for the term résonnent (resonate): explosions from Syrian terror attacks had not simply happened the previous day they were reverberating in the minds of the demonstrators.

It is through cycles of such emergence that a dynamic system evolves and may change fundamentally on particular levels over time. In newswriting, new procedures, skills, policies, workflows, and technologies emerge. However, the system maintains its overall identity as long as salient properties change in line with contextual changes. Newswriting is, after centuries of change, still bound to investigation, facts, relevance, recency, and broad impact in a context of public discourse which has also changed in similar ways to newswriting itself. In the LEBANON case, this means mapping traditional expectations of Swiss media politics with new media market demands:

R.G. overcame the critical situation of using brash stereotypes when under time pressure. Instead of catering to the market and resorting to predictable images that could overshadow publicly relevant developments, he absorbed his source material, listened to what was being said, and discerned what was important in the pictures. In doing so, he was able to discover a gentle access to the topic that allowed him to produce a coherent and fresh 
story and at the same time managed to reflect the political finesse required by his employer's remit of promoting public understanding.

Changing in line with contexts means changing in mutual response, in co-adaptation and, in the long term, co-evolution. Elements and relations of a dynamic system perpetually interact with one another, within and beyond the system. Thus, emergence on one particular level of a dynamic system motivates change throughout the system, the connected systems and the context - and feeds back to that level as the co-adapted context fuels future activity. That is what happens if faster technology accelerates newswriting and enables tighter deadlines, which call for even faster technology. The behavior of a dynamic system changes, but since the context likewise changes, the system maintains its identity - dynamically.

Self-similarity is another characteristic of dynamic identity. Change happens along scalable patterns, self-similar on several levels and timescales, such as tranquility in the LEBANON case. However, the emergent solution in the critical situation of this journalist's writing process also makes a case for emergent solutions to similarly critical problems within conflicting expectations on more general levels. On an institutional level, emergent solutions are needed by R.G.'s employer, the Swiss public service provider SRG SSR, which has to find its way out of increasingly intense conflicts between the traditional public mandate and the pressure of media markets. On a societal level, emergent solutions are urgently needed by journalism in the face of media convergence.

Public service broadcasting companies are among the most important broadcasting companies in Europe. In Switzerland, the public broadcaster, SRG SSR, also has the highest ratings. As a public service institution, SRG SSR has a federal, societal, cultural, and linguistic mandate to fulfil: to promote social integration by promoting public understanding. "In their programs SRG SSR promotes understanding, coherence, and exchange among the parts of the country, linguistic communities, cultures, religions, and social groups [...]" (Translation of the programming mandate 2007, article 2, paragraph 2).

As a media enterprise, though, SRG SSR is subject to market and competitive forces. Losing audience would mean losing public importance. Therefore, the mandate presupposes that reaching the public will promote public understanding. In the research project in which the Lebanon case was analyzed, ${ }^{13}$ the researchers investigated how those working for the broadcaster deal with the following tasks a) fulfilling their public duty by providing programs and items that contribute to the public debate and pro- 
mote public understanding, while also b) actually reaching the public in an increasingly competitive media market, and finally c) dealing with growing economic pressure and increasingly faster technological change.

The overall findings show that the knowledge of how to bridge the public mandate and market forces cannot be identified in executive suites, but in newsrooms. Whereas the managers usually are frustrated by the expectations of media politics, some experienced journalists find solutions to overcome the conflict between the public mandate and the market. These solutions tend to emerge when the journalists tackle complex and unexpected problems in critical situations within their daily routines, as R.G. did.

The following conclusions could be drawn from these findings: The conditions for emergent solutions in news teams need to be systematically improved top-down by media politics and media management, and the tacit knowledge involved must be systematically identified bottom-up at the workplaces and then be made available to the whole organization. Based on these recommendations, the stakeholders working in media policy, media management, media practice, and media research have set up follow-up activities for knowledge transformation, such as systematic organizational development, consulting, coaching, and training.

\section{Outcomes: Conceptualizing and modeling complex dynamics}

Doing research in the framework of DST means exploring behavior within and across very different levels and timescales. As DST considers everything to be connected with everything else, decontextualizing and atemporalizing single phenomena is out of the question. Instead, DST research foregrounds certain aspects, such as the role of emergence in individual writing processes, and investigates them in more detail while remaining open to contextual behavior that might explain change. This calls for multimethod approaches combining in-depth case studies and large corpora as well as analysis and modeling.

Case studies can reveal where, when, how, and why change happens on the micro level of situated activity. As the LEBANON case has shown, a new pattern of process management or product design can emerge in the critical situation of newswriting when a journalist tries to juggle conflicting expectations. If the new pattern succeeds, it might become part of that journalist's repertoire. Understanding such micro processes means shifting from a static view of newswriting (see Section 1, above) to the dynamic perspec- 
tive of DST (Section 2). An evaluation perspective (Section 3) identifies control parameters of micro change. Finally, an identity perspective (Section 4) allows us to see the micro development as representing a principle that also underlies changes on higher levels and larger timescales. ${ }^{14}$

Tracing micro development needs dense corpora with rich procedural data over short periods of time: the activities of collaborative writing and conferencing in the newsroom have to be captured as broadly and in as much detail as possible. In contrast, tracing change on macro levels and timescales of the newsroom, journalism, or even society at large needs elaborate corpora. The samples have to be wide enough to allow for generalization; the sampling intervals close enough to infer variability and shifts in state; and the data collection prolonged enough to grasp long-term change. Combining dense and large corpora enables researchers to situate micro development within the context of macro development.

In the research project, the LEBANON case study is part of, newswriting was conceptualized as balancing practices in a complex context of conflicting expectations. Newswriting, then, was metaphorically modeled as a helix of 16 interacting fields of situated activity in an environment of conflicting expectations (Figure 4).

The dynamic system of situated text production can be described in terms of fields of relevant activity (Figure 4). It begins when writers understand and accept a production task (Defining the task) and ends when they send the results of their work along the production chain, such as to colleagues who assemble news programs from individual items (Implementing the product). In between, reading processes (Source reading and Product reading) interact with writing processes on various time frames and scales (from grapheme to text version levels). In the inner circle of the writing process, four phases recur and overlap, each dominated by activities which contribute, on their specific levels, to the incremental production of the text. Goal setting typically focuses on the text as a whole, Planning on sequences of text parts such as paragraphs, and Controlling on the formulations under construction. Monitoring, in contrast, traces the results of the production process throughout all of the levels. 


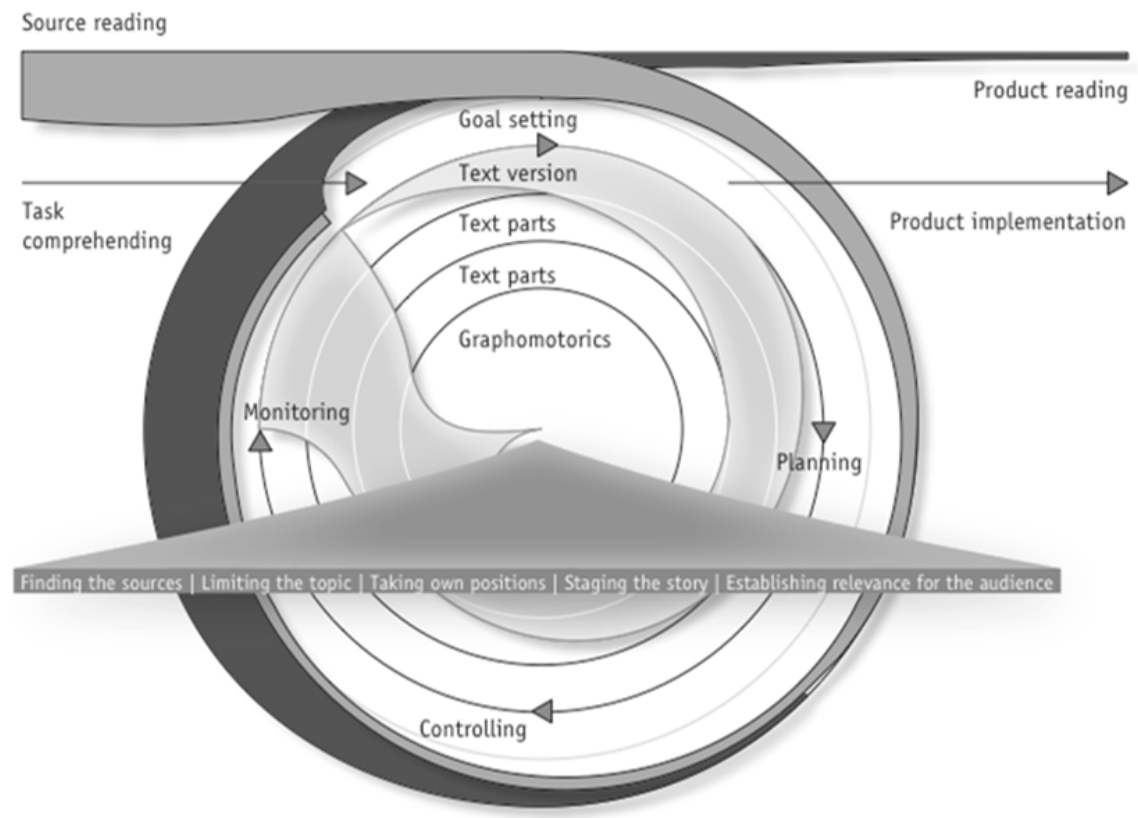

Handling tools environment | Handling task environment | Handling social environment

Figure 4. The dynamic system of situated text production.

However, it is not only existing and emerging texts that writers deal with when producing texts. They also handle their social environment, such as interactions with superiors and co-writers, the tools environment, such as workplaces and computers, and the task environment, such as other jobs that need to be done at more or less the same time. Whereas the eleven fields outlined above refer primarily to managing processes, the five other fields of activities are directly oriented to the emerging text products. These are: identifying sources and integrating source materials (Finding the sources); deciding on and sticking to the subject (Limiting the topic); defining and communicating one's own role and stance in the text (Taking own position); addressing presumed needs and interests of the audience (Establishing relevance for the audience); and mapping linguistic varieties, styles, genres, and dramaturgy (Staging the story). In the Lebanon case, the emerging solution of the "tranquil" leitmotif helped the journalist to produce a coherent and fresh story (Staging the story) and at the same time to present new information that reflects political subtleties (establishing rele- 
vance for the audience) - and thus to overcome the conflict between market demands and the mandate of promoting public understanding.

However, DST can be more than a useful metaphor in scientific approaches to writing processes. Research can also proceed heuristically, starting with assumptions instead of data. In this case, the processes of change in a dynamic system are reconstructed through dynamic models: simulations and analogies which are tested against reality for best fit. The outcome of a computer simulation is compared with observations of the real-world system under investigation. Relations are redesigned and parameters adjusted until the model behaves like the observed reality. The dynamic model simulates change through iteration of algorithms: rules are applied in loops where the output of one loop is the input for the next. Thus, the mechanisms of change in the model are exactly known and can be taken as metaphors for the principles of change in the real world system.

Based on data of hundreds of cases similar to the LEBANON case, models of writing phases have been extracted and are being tested. In a subsequent interdisciplinary research project, ${ }^{15}$ writing phases will be modeled as time periods with predominant activities. These are identifiable in the data throughout scales and time frames by more or less homogeneous (predictable) time series dynamics between critical states (with rather unpredictable ends). First findings show, for example, that the two dominant progression types of the LEBANON case, linear writing (phase A in Figure 2 above) and chiseling (Phase E) support a prediction of successful text production in terms of coherence, whereas chaotic jumping back and forth as dominant phase would allow for predictions of coherence gaps.

Thus, changing one single word, depending on the context, can take the dynamic system of writing to strong symbols and leitmotifs - or to weak cohesion and coherence. It is a tricky, complex matter, and that is what makes writing research and DST a promising couple.

\section{Notes}

1. As the purpose of writing research is to explain processes and thus dynamics, I prefer the term Dynamic Systems Theory (DST) to other widespread terms which focus on other key properties of such systems, such as complexity, nonlinearity or adaptivity. In my summary of DST, I draw primarily on LarsenFreeman and Cameron (2008), who broach the issue of "the dynamics of written discourse" (Larsen-Freeman and Cameron 2008: 185-188) - a reasonable starting point for combining DST and linguistics of newswriting. 
2. For further discussions of the domain concept see Werlen (2004). I would like to take the opportunity at this point to express my warmest appreciation to Iwar Werlen, who has sustainably inspired me to investigate language use in realworld contexts and writing in professional domains in detail - always keeping the "so what?" question in mind.

3. For recent discussions of contexts of newswriting see for example Cotter (2009) or Catenaccio et al. (2011).

4. For further discussions of progression graphs in particular and progression analysis in general see Perrin (2003), Perrin (2006), or Perrin and Ehrensberger-Dow (2008).

5. S-notation was developed by Kerstin Severinson-Eklundh and her research team. For further discussions see for example Kollberg and SeverinsonEklundh (2002) and Severinson-Eklundh and Kollberg (2003).

6. tsr_tj_070212_1220_guillet_frame, lines 16-18: “c'était déjà pour la télévision, pour une émission qui s'appelait la course autour du monde, c'était pendant mes études de lettres"

7. tsr_tj_070212_1220_guillet_frame, lines 36-39: "et après dix ans à la rubrique internationale où $\mathrm{j}$ 'ai fait passablement de voyages, de reportages à l'étranger, pendant dix ans ça fait pas mal de séjours et reportages à l'étranger"

8. tsr_tj_070214_1230_guillet_libanon_review, lines 946-954: "moi je fais une photographie de ce qui se passe pendant la matinée, puisque ce premier sujet passe à douze heures quarante cinq. au liban cette manifestation, elle draine une foule immense, comme on le voit sur les images, et je dois montrer que cette foule répond à un certain nombre d'aspirations, et je dois donner les clés pour la personne qui n'y connaît pas grand chose"

9. tsr_tj_070214_1230_guillet_libanon_review, lines 985-987: “je fais attention vraiment aux images, par exemple je ne m'attendais pas à voir ces bateaux, ça je savais que j'allais le mettre"

10. Larsen-Freeman and Cameron (2008) illustrate this concept of dynamic stability with the "constant adjustments [that] are required to overcome the force of gravity in order for us to stand erect on two feet" (87) and with swimming: "without the extra input of energy produced by waggling hands or feet, floating would cease. [...] the movements of the swimmer are adaptations made in response to the environment - to the need to prevent sinking." (33)

11. Holland (1998: 2), describes this phenomenon as "much coming from little".

12.tsr_tj_070214_1230_guillet_libanon_verbal, lines 180-185: “j'aime bien cet adjectif parce que pour l'instant, les mots ils résonnent dans la tête des gens, tranquille c'est pour l'instant le point de cette manifestation, elle est plutôt bon enfant pour l'instant, parce qu'il n'y a pas eu de heurts, donc je mets la voie tranquille"

tsr_tj_070214_1230_guillet_libanon_review, lines 1019-1024: “mais dans toutes les images que j'ai vues pour l'instant, c'est une manifestation qui ne dé- 
génère pas, donc si je peux saupoudrer le texte de mots qui résonnent justes par rapport à ce qui a l'air de se passer sur place, je les garde"

13. The research project IDÉE SUISSE: LANGUAGE POLICY, NORMS, AND PRACTICE AS EXEMPLIFIED BY SwISS RADIO AND TELEVISION was funded from 2005 to 2007 by the Swiss National Science Foundation. It is part of the National Research Program 56, LANGUAGE Diversity AND Linguistic COMPETENCE IN SWITZERLAND, 2005-2010. Outlines and reports of the program and its projects (in German, French, and Italian) can be found on www.nfp56.ch. For a discussion of the project see, e.g., Perrin (2011).

14. Thelen and Corbetta (2002) describe the study of micro development as "the study of the processes of change, not only the endpoints." (59) "The goal of microdevelopmental studies is to understand change itself: what are the mechanisms by which people forgo old ways of behaving and adapt new ones." (60) Micro developments are "the motors of change" (59). Because of the selfsimilarity of dynamic systems, it can be assumed that "the processes that cause change in a matter of minutes or hours are the same as those working over months or years. In other words, the general principles underlying behavioral change work at multiple time scales." (60)

15. The aim of the Modeling Writing Phases project, funded from 2011 to 2013 by the Swiss National Science Foundation, is to statistically model and explain writing phases as temporal procedural units. Typical dominant writing actions such as "formulating" or "source reading" are identified and related to writing phases. The project attempts to overcome limitations of traditional writing phase concepts that are based on introspection or single case studies. On the methodological level of the project, DST-informed statistical techniques beyond those normally associated with corpus linguistics are developed. For a discussion of initial results see Perrin and Wildi (2010) and Perrin et al. (2011).

\section{References}

Beckner, Clay, Richard Blythe, Joan Bybee, Morten H. Christiansen, William Croft, Nick C. Ellis, John Holland, Jinyun Ke, Diane LarsenFreeman, and Tom Schoenemann

2009 Language is a complex adaptive system. Position paper. Language Learning 59 (1): 1-26.

Cameron, Lynne, and Alice Deignan

2006 The emergence of metaphor in discourse. Applied Linguistics 27 (4): 671-690. 
Catenaccio, Paola, Colleen Cotter, Mark Desmedt, Giuliana Garzone, Geert Jacobs, Lutgard Lams, Felicitas Macgilchrist, Daniel Perrin, John E. Richardson, Tom Van Hout, and Ellen Van Praet

2011 Position paper. Towards a linguistics of news production. Journal of Pragmatics 43 (7): 1843-1852.

Cotter, Colleen

2009 Newstalk. Shaping the Language of News. Cambridge: Cambridge University Press.

Ellis, Nick C., and Diane Larsen-Freeman

2006 Language emergence. Implications for applied linguistics. Introduction to the special issue. Applied Linguistics 27 (4): 558-589.

Halliday, Michael Alexander Kirkwood

1973 Explorations in the Functions of Language. New York: Elsevier.

Harris, Randy Allen

1993 The Linguistic Wars. New York: Oxford University Press.

Holland, John Henry

1998 Emergence. From Chaos to Order. Redwood City, CA: AddisonWesley.

Kollberg, Py, and Kerstin Severinson-Eklundh

2002 Studying writers' revising patterns with S-notation analysis. In Contemporary Tools and Techniques for Studying Writing, C. Michael Levy, and Thierry Olive (eds.), 89-104. Dordrecht: Kluwer Academic Publishers.

Lantolf, James P.

2006 Language emergence. Implications for applied linguistics. A sociocultural perspective. Applied Linguistics 27 (4): 717-728.

Larsen-Freeman, Diane

2006 The emergence of complexity, fluency, and accuracy in the oral and written production of five chinese learners of English. Applied Linguistics 27 (4): 590-619.

Larsen-Freeman, Diane, and Lynne Cameron

2008 Complex Systems and Applied Linguistics. 2nd ed. Oxford: Oxford University Press.

MacWhinney, Brian

2006 Emergentism. Use often and with care. Applied Linguistics 27 (4): 729-740.

Perrin, Daniel

2003 Progression analysis (PA). Investigating writing strategies at the workplace. Journal of Pragmatics 35 (6): 907-921.

2006 Progression analysis. An ethnographic, computer-based multimethod approach to investigate natural writing processes. In Writing and Digital Media, Luuk Van Waes, Mariëlle Leijten, and Chris Neuwirth (eds.), 175-181. Amsterdam et al.: Elsevier. 
2011 "There are two different stories to tell" - collaborative text-picture production strategies of TV journalists. Journal of Pragmatics 43 (7): 1865-1875.

2012 The Linguistics of Newswriting. Amsterdam/New York et al.: John Benjamins.

Perrin, Daniel, and Maureen Ehrensberger-Dow

2008 Progression analysis. Tracing journalistic language awareness. In L'analyse linguistique des discours des médias: théories, méthodes en enjeux. Entre sciences du langage et sciences de la communication et des médias, Marcel Burger (ed.), 155-182. Québec: Nota Bene.

Perrin, Daniel, Mathias Fürer, Thomas Gantenbein, Beate Sick, and Marc Wildi

2011 From Walking to Jumping. Statistical Modeling of Writing Processes. Electronic Proceedings of the JACET 50th commemorative international convention. Fukuoka: Jacet.

Perrin, Daniel, and Marc Wildi

2010 Statistical modeling of writing processes. In Traditions of Writing Research, Charles Bazerman (ed.), 378-393. New York: Routledge.

Sealey, Alison, and Bob Carter

2004 Applied Linguistics As Social Science. London et al.: Continuum.

Severinson-Eklundh, Kerstin, and Py Kollberg

2003 Emerging discourse structure: computer-assisted episode analysis as a window to global revision in university students' writing. In The Pragmatics of Writing, Daniel Perrin (ed.), 869-891. (Journal of Pragmatics. Special Issue 35/6.) Amsterdam et al.: Elsevier.

Thelen, Esther, and Daniela Corbetta

2002 Microdevelopment and dynamic systems. Applications to infant motor development. In Microdevelopment. Transition Processes in Development and Learning, Nira Granott, and Jim Parziale (eds.), 59-79. Cambridge: Cambridge University Press.

Vygotski, Lew S.

1978 Mind in Society. The Developments of Higher Psychological Processes. Cambridge: Harvard University Press.

Werlen, Iwar

2004 Domäne. In Sociolinguistics. An International Handbook of the Science of Language and Society. Volume 1 / Soziolinguistik. Ein internationales Handbuch zur Wissenschaft von Sprache und Gesellschaft. 1. Teilband, 2nd ed., Ulrich Ammon, Norbert Dittmar, Klaus J. Mattheier, and Peter Trudgill (eds.), 335-341. (Handbücher zur Sprach- und Kommunikationswissenschaft 3.1.) Berlin/New York: De Gruyter. 